A R T I G O

\title{
CRONOTOPIAS DA INTIMIDADE CATASTRÓFICA: TESTEMUNHOS SOBRE A COVID-19 NO JORNAL NACIONAL
}

Chronotopias of catastrophic intimacy: testimonies about COVID-19 in the Jornal Nacional

Cronotopías de intimidad catastrófica: testimonios sobre COVID-19 en el Jornal Nacional

\author{
FLAVIA PINTO LEIROZ ${ }^{*}$ \\ IGOR SACRAMENTO ${ }^{\text {II** }}$
}

DOI: https://doi.org/10.1590/S2178-149420210209

\footnotetext{
'Programa de Pós-Graduação em Comunicação e Cultura, Universidade Federal do Rio de Janeiro - Rio de Janeiro (RJ), Brasil. *Jornalista, redatora e revisora, em estágio pós-doutoral, Escola de Comunicação e Cultura, Universidade Federal do Rio de Janeiro (flavialeiroz@gmail.com)

(D) https://orcid.org/0000-0002-6761-466X

"Programa de Pós-Graduação em Informação e Comunicação em Saúde, Fundação Oswaldo Cruz, e Programa de PósGraduação em Comunicação e Cultura, Universidade Federal do Rio de Janeiro - Rio de Janeiro (RJ), Brasil.

* *Professor e coordenador do Programa de Pós-Graduação em Informação e Comunicação em Saúde, Fundação Oswaldo Cruz (igorsacramento@gmail.com)

(D) https://orcid.org/0000-0003-1509-4778
}

Artigo recebido em 01 de janeiro de 2021 e aprovado para publicação em 11 de março de 2021. 


\title{
RESUMO
}

Este texto tem como objetivo principal observar como as narrativas do Jornal Nacional sobre a pandemia de COVID-19 organizam-se dentro de um cronotopo da intimidade catastrófica, por meio do qual a narrativa pessoal se dá, sobretudo, em espaços que relevam a intimidade, transbordando o privado para 0 público, borrando as fronteiras entre a casa e o trabalho e entrelaçando corpo e espaço numa experiência de suspensão temporal. Concluímos, por meio das narrativas analisadas, que a pandemia de COVID-19, pela narrativa do telejornal, instalou um tempo suspenso ou interrompido, mas muito significativo para a história contemporânea.

PALAVRAS-CHAVE: COVID-19; Tempo; Mídia; Intimidade; Catástrofe; Cronotopo.

\begin{abstract}
The main objective of this text was to observe how the Jornal Nacional's narratives about the COVID-19 pandemic are organized within a chronotope of catastrophic intimacy, through which the personal narrative takes place, above all, in spaces that reveal intimacy, overflowing the private to the public, blurring the boundaries between home and work and intertwining body and space in an experience of temporal suspension. It was concluded, through the narratives analyzed, that the COVID-19 pandemic, by the narrative of the newscast, installed a suspended or interrupted time, though very significant for contemporary history.
\end{abstract}

KEYWORDS: COVID-19; Time; Media; Intimacy; Catastrophe; Chronotope.

\section{RESUMEN}

Este texto pretende observar cómo se organizan las narrativas del Jornal Nacional sobre la pandemia de COVID-19 dentro de un cronotopo de intimidad catastrófica, a través del cual se desarrolla la narrativa personal, sobre todo, en espacios que elevan la intimidad, desbordando lo privado al público, difuminando los límites entre el hogar y el trabajo y entrelazando cuerpo y espacio en una experiencia de suspensión temporal. Concluimos, a través de las narrativas analizadas, que la pandemia COVID-19, a través de la narrativa de las noticias televisivas, instaló un tiempo suspendido o interrumpido, pero muy significativo para la historia contemporánea.

PALABRAS CLAVE: COVID-19; Tiempo; Medios de comunicación; Intimidad; Catástrofe; Cronotopía. 


\section{INTRODUÇÃO}

m março de 2020, o Brasil começou um processo de isolamento social por conta das
medidas de prevenção durante a pandemia de COVID-19. Milhões de pessoas tiveram suas rotinas alteradas pela necessidade de quarentena. Segundo dados da InLoco, em 22 de março, $62,2 \%$ da população brasileira estava em casa': escolas, escritórios, bares, restaurantes e comércio foram fechados. Home office, educação a distância e entregas em domicílio ganharam novas dimensões e novos significados porque, especialmente para as classes médias urbanas, deixaram de ser escolhas e passaram a ser necessidades para se tentar evitar a contaminação e o adoecimento.

A saída do espaço doméstico para uma multiplicidade de outros espaços e formas de vida foi temporariamente suspenso. As marcas temporais, vinculadas a um cotidiano que preenchia espaços, condensaram-se. Nossa capacidade de estruturar, gerenciar e manipular nossa experiência do tempo transformou-se.

Leonor Arfuch (2005: 248) afirma que o que nos define são os lugares que ocupamos no tempo de nossas vidas: "impossível pensar a vida sem o cenário de sua efetivação, mas estamos sujeitos à lógica e à angústia do tempo". Essa temporalidade, que é também espacialidade, envolve geografias, lugares, moradias, espaços onde nossos corpos aparecem frequentemente marcados pela cronologia, mas também por relações afetivas.

Assim, quando Arfuch (2005) lança o conceito de cronotopias da intimidade, contido em nosso título, remete-o a uma articulação peculiar e simbólica entre espaço, tempo e afeto que destaca um lugar, um objeto, um gesto, um texto como âncoras de significados múltiplos e emblemáticos. Arfuch toma como base Bakthin e sua noção de cronotopo, conceito que marca a teoria dos gêneros discursivos. Tal como na literatura, o cronotopo assinala uma correlação essencial das relações espaço-temporais: o tempo condensa-se na medida em que o espaço se intensifica, imerso que está no movimento do próprio tempo, do sujeito/personagem, da história. Para Bakhtin (2018), torna-se de fundamental importância fixarmo-nos na expressão de inseparabilidade do espaço e do tempo, compreendendo este como a quarta dimensão do espaço. Uma vez que a mente humana tem a experiência do tempo, principalmente cronológico, mas não sua representação concreta, ela concebe-o por intermédio de imagens espaciais.

Por isso, ou por causa disso, tempo e espaço tornam-se também e simultaneamente indissociáveis de um valor emocional. Transformam-se em ponto nodal da trama, que dá sentido, em sua dimensão configurativa, às ações e aos personagens. Opera sempre no presente da narração, assim como na carga de valor que carrega pela história que tece e pela tradição que envolve. 
No entanto, vale destacar que o conceito trabalhado pela teórica argentina tem como referência concepções espaço-temporais provocadas principalmente pela sensação de aceleração do tempo, experimentado nas relações socioeconômicas do mercado de trabalho contemporâneas e pela forte influência midiática. Essas duas diferentes experiências e vivências causariam a percepção de instantaneidade, de presentificação do mundo em que vivemos.

Para nós, dessa forma, refletir sobre a questão da temporalidade, ou seja, a forma como se vive na duração, como pontua Marialva Barbosa (2017), envolve discutir cronotopias da intimidade, o espaço-tempo-afeto, a partir de tramas narrativas que enredam percepções e sentidos de tempo midiático, memória, corpo e catástrofe.

Para Arfuch (2005), a união do espaço-tempo com o afeto desdobra-se como um conceito que se caracteriza, por exemplo, pela experiência da e na casa/do e no lar. Há aqui uma concretude - casa e corpo entrelaçam-se na certeza de uma materialidade - que se manifesta em nossa sensação de proteção contra intempéries da vida social e natural. Objetos, espaços, lembranças enredam-nos em memórias que superam cronologias.

Em 2020, o tempo em casa foi redimensionado e encontrou-se inexoravelmente com o tempo midiático, dependente e, ao mesmo tempo, produtor da espessura temporal contemporânea. Marialva Barbosa, ao refletir sobre inter-relações entre tempo, tempo histórico e tempo midiático, mostra-nos que o fluxo temporal promovido pelas tecnologias avançadas de comunicação e a velocidade da circulação de informação modificaram a experiência temporal cotidiana:

[...] qualquer instante se transforma em tempo de frenesi que dura continuamente [...]. Há o tempo em que todos devem estar conectados, em que todos podem ser alcançados sem demora, o tempo real, que abole prazos e tempos mortos. Instaura-se um tempo sem intervalo, fluido, numa espécie de eterno presente (Barbosa, 2017: 21).

No mundo pandêmico de 2020, isso é sentido e experimentado intensamente. Na prática cotidiana e inflexível, o tempo-espaço que nos constrange ao isolamento social em casa é o mesmo que nos aprisiona em um eterno presente, sem expectativas de futuro. Nossa casa, considerada refúgio, vista como proteção inequívoca da existência, é invadida por câmeras ligadas em celulares e computadores, permitindo que pessoas não incluídas no rol daquelas que poderiam partilhar de nossa intimidade entrem em nosso quarto, estejam conosco num outro tempo-espaço e invadam nossa privacidade. Trabalho e casa misturam-se sob o mesmo teto, e as informações da rua chegam pela televisão, trazendo a tragédia e a catástrofe para a sala.

Dados do Instituto Brasileiro de Opinião Pública e Estatística (Ibope) mostram que a conexão da sociedade com a televisão aumentou desde o início da quarentena: $+17 \%$ de televisores ligados na média diária em todo Brasil e $+20 \%$ do tempo dedicado à televisão, 
que agora chega a 7 horas e 32 minutos diários². 0 perfil do público também mudou: o número de espectadores entre 12 e 17 anos cresceu $21 \%$ e, entre pessoas de 35 a 49 anos, 0 aumento chegou a $22 \%$.

Desde 26 de fevereiro, quando foi confirmado o primeiro caso do novo coronavírus no Brasil, o telejornalismo integra o quadro de serviços considerados essenciais. Nesse novo contexto, Rede Globo e Jornal Nacional (JN), com edições diárias na televisão aberta, de segunda a sábado, das 20 h30 às $21 \mathrm{~h} 30$, destacam-se $\mathrm{e}^{3}$.

Segundo dados da Kantar IBOPE Media, de 16 de março a 30 de junho, 90\% dos jovens brasileiros entre 15 e 29 anos procuraram o jornalismo da Globo para se informar sobre a pandemia da COVID-19 e os seus desdobramentos. 0 público jovem é responsável por $11 \%$ de todo o crescimento. $0 \mathrm{JN}$ ganhou mais 1,5 milhão de jovens por dia em relação ao mesmo período de $2019^{4}$.

Essa faixa etária foi a que teve rotinas mais alteradas por estar, respectivamente, em idade escolar e no grupo que representa $35 \%$ da força de trabalho brasileira. Houve, ainda, aumento de audiência nas diferentes classes sociais, sendo de $26 \%$ na classe $A B$, de $16 \%$ na classe $\mathrm{C}$ e de $8 \%$ na classe $\mathrm{DE}^{5}$.

Começamos, então, a observar mudanças em posturas, gestos, imagens de fundo, quadros e posicionamentos em editoriais do JN. 0 objetivo era a leitura de caminhos possíveis para entender o aumento da audiência e as relações midiáticas e temporais estabelecidas sob a égide de um momento de crise mundial.

0 editorial de 6 de maio, lido por William Bonner, âncora do JN ao lado de Renata Vasconcellos, direcionou nossa análise:

0 número muito grande de mortes, de repente, em um desastre sempre assusta. As pessoas levam um baque. Morreram mais de 250 pessoas em Brumadinho. É uma tragédia. Nos Estados Unidos, em 2001, morreram quase 3 mil nos atentados de 11 de setembro. Três mil, assim, de repente. Mas, quando as mortes vão se acumulando ao longo de dias e semanas, como acontece agora, na pandemia, esse baque se dilui e as pessoas vão perdendo a noção do que seja isso: oito mil vidas acabaram. Eram vidas de pessoas amadas por outras pessoas — pais, filhos, irmãos, amigos, conhecidos (Jornal Nacional, 06 de maio de 2020).

Nessa fala, que reúne expressões constritas e gestos que tentam simular conversa cotidiana, Bonner relaciona pandemia e catástrofe com a difícil tarefa de assimilação por parte da população com algo que vai além da ruptura de rotinas e do redimensionamento de espaços. Envolve questões relacionadas a percepções de tempo, corpos e afetos.

Catástrofe, segundo Pomian (1977: 789), "é aquela mudança negativa que causa ou ameaça provocar mutação na solução de continuidade. A catástrofe quebra o tempo humano, 
abre um abismo entre passado e futuro, ameaça quebrar o elo entre as gerações". No sentido forte, catástrofe é ameaça contra a ordem do mundo e pode corresponder a um evento político, um desastre natural, um crime ambiental. É também matriz de identidade coletiva e determina, com frequência, que aqueles que a experimentam conjuntamente se organizem comunitariamente.

Essas considerações preliminares são roteiros e molduras utilizadas para análise de algumas edições do JN exibidas entre março e junho de 2020. A construção deste texto acompanha caminho percorrido na articulação entre teoria e observação empírica. Dividido em três partes, expõe primeiro a articulação entre tempo midiático, tempo narrativo e cronotopo. Essas questões são premissas para compreender a relação entre cronotopias da intimidade e a implosão da porta da casa, o redimensionamento do dentro e do fora, do público e do privado, e o espaço ocupado pela televisão. Com esse percurso, defendemos que o tempo da pandemia pode ser sentido como catastrófico e tem na mídia um canal de construção de sentidos diante da perplexidade do isolamento e das mortes. E é nos lugares de memória que habitam e ocupam nossos corpos e gestos que entendemos as mudanças feitas no JN e a escolha por testemunhos como força jornalística deste momento. A união de espaço-tempo e afetividade ativa saberes e memórias que perpassam corpos, sentidos e espaços que ocupamos. Os cronotopos que escolhemos como pontos nodais são exemplos disso.

\section{"NA QUARENTENA, TODOS OS DIAS SÃO UM DIA SÓ"6}

o dia 20 de junho, Renata Vasconcellos, parceira de bancada de Bonner, lê em editorial
do $J N$ : Uma nação chora seus mortos, se solidariza com aqueles que perderam pessoas queridas. Cinquenta mil. Diante de tragédia como essa, uma nação para, ao menos um instante, em respeito a tantas vidas perdidas. É o que o Jornal Nacional está fazendo agora diante desses rostos que temos perdido desde março (Jornal Nacional, 20 de junho de 2020).

E Bonner acrescenta:

O JN já pediu, você lembra, que a gente parasse para respirar porque tudo vai passar. 0 JN já lembrou que vidas perdidas não podem ser vistas só como números. E a gente pede mais uma vez, e repete também, que 50 mil não são um número, são pessoas que morreram numa pandemia. Elas tinham família, mães, pais, tios, avós, colegas de trabalho [...]. A história vai registrar também aqueles que se omitiram, que foram negligentes, desrespeitosos. A história atribui glória e atribui desonra. E história fica para sempre (Jornal Nacional, 20 de junho de 2020). 
0 texto, mais uma vez, convoca tempo e número de vidas perdidas. A narrativa inclui o próprio JN como personagem, e, mesmo na contradição de desumanizar o texto, Bonner e Renata, mais do que locutores, inserem-se como testemunhas do tempo midiático que enunciam. Eles seguem, com mais intensidade, mudanças que se desdobram desde 2015: o lugar de corpos e falas de locutores e repórteres vai se modificando, tornando-se flexível, e eles vão ocupando efetivamente as cenas dos acontecimentos como "atores" (Fausto Neto, 2012).

0 tempo contado em número de mortes remete simultaneamente a um passado e um looping eterno de um presente distendido: "E história fica para sempre". O historiador Paul Veyne (1971) diz que o que se opõe ao tempo, assim como à eternidade, é nossa atualidade. É ela que concretiza uma realidade vivida e compreendida no tempo-espaço de nossa existência. Essa constatação encontra-se com o que Marialva Barbosa (2017) aponta como parte do trabalho dos meios de comunicação. No processo de construção do passado como história, são inseridas em suas narrativas materialidades que presentificam fatos e ações ocorridas: "podemos dizer que os meios de comunicação já produzem suas narrativas visando sua reapropriação no futuro, ou seja, como documentos para a história" (Barbosa, 2017: 22).

Aqui, o tempo passado — "O JN já pediu, você lembra" — , ao compararmos com o editorial de 6 de maio, é muito recente. Na recordação que se concretiza narrativamente, há a proposta de articular e organizar a experiência do tempo. Paul Ricoeur (2007) diz que história não é o estudo da execução de um plano já traçado, mas o da ação. Implica entender sucessão de ações, pensamentos, sentimentos que caminham em certa direção.

Barbosa (2007) ressalta que Ricoeur relaciona a qualificação do tempo diretamente ao modo narrativo, da mesma forma que é pela narrativa que o tempo pode ser experimentado e apropriado. 0 modo narrativo pressupõe instauração de um tempo próprio: o tempo humano, que envolve indicação de agentes e sofredores das ações dos acontecimentos.

Dentro de casa, a narrativa do telejornal solicita inclusão de afeto, memória e percepção catastrófica de vidas perdidas. Em 30 de abril, uma entrevistada afirma que, dentro de casa, todos os dias são um dia só, como se a vida tivesse ficado em suspenso. Porém notícias insistem em mostrar que os dias não se repetem e informam: cinquenta mil mortes entre março e junho.

\section{"ESTAMOS AQUI PARA SALVAR O AMOR DE ALGUÉM"7}

a teoria literária e na filosofia da linguagem, cronotopo é como configurações de tem-
po e espaço são representadas na linguagem e no discurso. 0 termo foi desenvolvido 
por Mikhail Bakhtin em seu ensaio "Formas do tempo e do cronotopo no romance", de 1937, como elemento central em sua teoria do significado na linguagem e na literatura. Bakhtin mostrou como diferentes gêneros literários operavam com diferentes configurações de tempo e espaço, o que conferia a cada gênero seu caráter narrativo particular. Trata-se de uma unidade de análise para estudar a linguagem de acordo com proporção e características de categorias temporais e espaciais representadas num dado sistema linguístico, de acordo com visões de mundo ou ideologias particulares.

Bakhtin definiu cronotopo de forma tão ampla que era quase sem fronteiras. Segundo ele, damos sentido a todos os fenômenos, ou seja, incorporamo-los não apenas à esfera da existência espacial e temporal, mas também à esfera semântica: "qualquer intervenção na esfera dos significados só se realiza atrás da porta dos cronotopos" (Bakhtin, 1998: 362).

0 cronotopo não demanda análise transcendental, mas de formas da realidade como representações inscritas em específicas atividades sociais. Realiza fusão específica dos índices temporais e espaciais em um todo inteligível, sensível e concreto. Nessa fusão, a definição temporal (naquele momento) é inseparável da definição espacial (naquele lugar).

Nas palavras do próprio Bakhtin (1998: 355): "É no cronotopo que os nós do enredo são feitos e desfeitos. Pode-se dizer que a eles pertence o significado principal gerador do enredo". Desse modo, o cronotopo assume seu significado temático, mas também possui significado figurativo, dando ao tempo um caráter sensivelmente concreto: "no cronotopo, os acontecimentos do enredo se concretizam, ganham corpo e enchem-se de sangue".

Com isso, pode-se relatar o fato, dando informações precisas sobre lugar e tempo da representação. É evidente aqui que o cronotopo é realista, produz efeito de real a partir do detalhamento, da precisão cronotópica, tornando a representação verossímil, um real que se pode provar e que, por isso mesmo, é às vezes mais realista que o próprio real. Ao fundir os indícios temporais e espaciais, concretizando o espaço no tempo em regiões definidas do espaço, cria-se a possibilidade de se construir imagens dos acontecimentos no cronotopo (Bakhtin, 1998).

Assim, uma de suas principais funções é estabelecer zonas de contato com a realidade cotidiana, propiciando espaços de hibridização da realidade representada com a realidade que representa. Nesse sentido, a análise do cronotopo possibilita tanto, de modo mais restrito, a análise narrativa de obras literárias tomadas a partir de sua singularidade cronotópica quanto, de modo mais amplo, de estruturas genéricas mais estáveis, que tendem à invariabilidade e perduram ao longo da história, reconhecidas como parte de um mesmo gênero. Independentemente de como você os analisa, o tempo-espaço está inelutavelmente entrelaçado com o conceito de percepção8 ${ }^{8}$. 
Dessa forma, o cronotopo extrapola a literatura e estabelece-se, para nós, como possibilidade de leitura da narrativa jornalística no tempo presente. Mas como construímos nossa consciência de tempo-espaço e tornamos possível essa interação com a narrativa do telejornal? Como a perspectiva do cronotopo pode relacionar discursivamente fatos e afetos públicos na influência particular de uma relação construída no tempo de um mundo pandêmico?

Nesse contexto é que nos apropriamos do conceito de cronotopias da intimidade de Leonor Arfuch (2005). A peculiar relação entre espaço, tempo e investimento afetivo tem na vivência da casa como lar um cronotopo. É ali que depositamos nossas memórias em âncoras de sentidos que envolvem lembranças de gestos, objetos, pessoas, circunstâncias, cheiros e palavras que nos enredam em uma suspensão temporal movida pela localização espacial de afetos.

Arfuch trabalha para ajudar a compreender essa relação ainda experimentada como dualística de interior versus exterior, público e privado, com a metáfora da porta de Gëorg Simmel (1986), que tanto une como separa, funciona como meio de comunicação e isolamento. A porta une espaços porque os concebe separadamente. Por esse motivo, a porta tanto põe em evidência a continuidade física entre interior e exterior como explicita sua mútua implicação existencial.

No contexto da pandemia, a porta da casa incorpora a metáfora da dubiedade ainda mais intensamente. Agora, pode literalmente salvar sua vida, evitar contaminações. A casa, nossa intimidade, é valor a preservar diante da indeterminação do coletivo e da infinidade da rua. Por mais que a intimidade hoje possa ser percebida mais como nômade do que centrada num espaço físico, em situação de pandemia, a privacidade do lar e 0 que representa como aconchego voltam a ter um sentido de salvação do mundo exterior, fragmentado e tóxico.

No entanto, não há como separar público e privado com portas. As diferentes telas e câmeras ligadas, distribuídas ao alcance de nossos olhos dentro de nossa casa/nosso lar, demonstram que, no mundo contemporâneo, construímos sentidos pelo que vemos, lemos e percebemos, com base em enunciados e discursos que nos moldam cognitiva e emocionalmente (Leiroz, 2011).

É a intimidade pública, que Arfuch chama de novo paradoxo, interioridade sempre perpassada pela cultura e pelo mundo público, uma vez que inexiste isolada e inatamente. Além disso, o esboço da esfera do privado requer publicidade para se constituir. A vida que cada um abriga em seu interior, se não comunicada e compartilhada, é conjunto de sentimentos, percepções, vivências e lembranças. Observamos e somos observados pela comunicação, e é nesse ato, na construção de narrativas, que nos apresentamos e percebemos o outro. Na 
pandemia, em reuniões de trabalho, encontros sociais e aulas mediados pela tecnologia e por telas de disposivos, isso é ainda mais premente.

A televisão e as narrativas do JN — incluindo a inserção de novos quadros, que veremos mais tarde, em seu conteúdo - promovem a construção coletiva de nossa intimidade, sendo incluídas em nosso espaço biográfico.

A intimidade organizada narrativamente constrói-se também na articulação e hibridização do histórico e do cotidiano, nas posições relacionais e identificações contingentes de uma identidade coletiva. Os espaços biográficos, lugares que ocupamos no tempo de nossa existência física e narrativamente - casa, trabalho, escola, posts e perfis em redes sociais, entrevistas e imagens compartilhadas —- definem-nos para além das portas de nossas casas. Eles envolvem-nos, dessa forma, nas questões relativas à subjetividade, ao modo de narrar (dependentes das narrativas que ouvimos, vemos e testemunhamos) e à razão dialógica, estabelecendo complexas relações entre sujeito, linguagem, sociedade, discursos identitários, construção de narrativas, história e memória (Arfuch, 2010).

Para Arfuch (2005), são os meios de comunicação, e especialmente a televisão, que agem na construção pública de uma nova intimidade que se oferece como um consumo cultural fortemente hierarquizado. É, assim, pelo JN que também chegam apelos sobre o estar fora de casa no tempo da transmissão. A perspectiva de ter a casa como um cronotopo é atravessada pela possibilidade de ler e observar a narrativa do JN sob diferentes perspectivas cronotópicas.

\section{"NÓS TEMOS MEDO, MAS TEMOS CORAGEM TAMBÉM"9}

o dia 11 de maio, o JN estreia o quadro "Aqui Dentro", protagonizado por profissio-
nais da área de saúde. Bonner avisa que será um momento especial: "Aqui no JN, eles vão poder contar o que estão vendo, fazendo e sentindo". Todos os dias, os testemunhos, que duravam, em média, um minuto, encerravam a edição: "profissionais de saúde falam daquilo que veem dentro dos hospitais e, muitas vezes, põem para fora aquilo que sentem dentro do coração deles".

Na pandemia, profissionais de saúde estão na linha de frente para combater contaminações, sofrimento e morte. Nas incertezas que uma doença nova causa em todo mundo, eles são narrados pela mídia como aqueles capazes de vencer o medo ao saírem da segurança de suas casas para salvar vidas. Além disso, são convocados como testemunhas que sobrevivem ao perigo e, por isso, capazes de disseminar conhecimento sobre vírus, prevenção e possibilidades de cura. 
Nas imagens que circulam desde os primeiros registros de mortes causadas pela contaminação com o SARS-CoV-2, a quebra de rotinas, o número de mortes e as ruas desertas reverberam a sensação de estarmos vivendo uma catástrofe sem data específica, que se prolonga no tempo. Pomian (1997) defende que os efeitos da catástrofe, assim como a possibilidade de repará-los, escapam ao domínio de um grupo humano, superando sua capacidade técnica, cultural e econômica de absorção. Por isso, criam ruptura e uma série de oposições entre 0 antes e o depois. De acordo com Ribeiro et al. (2020: 61), catástrofe é ameaça radical à ordem cultural e social, uma vez que desestrutura a dimensão espacial de lugares naturais e materiais que servem como referência e suporte para a ordem social, assim como rearticula a dimensão temporal: "seu sentido mais comum, como sabemos, é o de desastre súbito e terrível, implacável, o que corresponde a um evento que causa numerosas vítimas e com inúmeras consequências para a comunidade".

No entanto, é preciso pensar no processo de produção de significados e sentidos que a catástrofe deve ter, justamente por suspender, mesmo que temporariamente, formas de nos relacionarmos com nossos corpos, e ao mesmo tempo, com espaços e tempos nos quais transitamos em experiências e vivências em sociedade. Para além do evento em si, é necessário inseri-lo em modos de reconhecimento e identificações sociais.

Nesse contexto, a mídia, em geral, e a televisão, em particular, ganham dimensão ainda maior. Silverstone (2011: 75) defende que, para transpor a catástrofe, a mídia utiliza imagens, molduras e narrativas que já existem em nossa cultura e em nossas mentes para reivindicar como familiar o que é complexo, estranho, extraordinário, suavizando o inesperado, o impensado e o medo. Isso "envolve seleção, representação, tradução", que tem consequências sobre como compreendemos o que ocorre no mundo, mas também como nos posicionamos em relação a isso (Silverstone, 2011: 76).

Segundo Bakhtin (1998), os valores biográficos moldam vida e arte, uma vez que são formas e valores da estética da vida. 0 valor biográfico é um princípio ordenador da narrativa (e da própria vida), que opera a partir de modelos de sucesso e de afetividade e por procedimentos narrativos, estratégias retóricas, pontos de vista, modalizações do ser e do dever ser. Tal conceito possui dupla valência, envolvendo ao mesmo tempo ordem narrativa e orientação ética. E é assim porque, para Bakhtin, o valor é a mediação entre experiência individual do mundo e o próprio mundo.

Esse ordenamento causa um efeito no plano da recepção, cria laços identificatórios, cumplicidades, modelos de herói, vidas exemplares e estabelece com os destinatários uma relação de diferença: "a vida como ordem, como devir da experiência, apoiado na garantia de uma existência 'real'" (Arfuch, 2010: 71). 
0 testemunho, ao impregnar a narrativa pessoal com a lógica da exemplaridade, configura sua autenticidade pela própria experiência narrada. Ter vivido tal experiência credencia o narrador - testemunha, sobrevivente ou vítima — como autoridade no que diz. Esse valor testemunhal nos relatos pessoais contemporâneos sobre acidentes, catástrofes, doenças, traumas e uma série de eventos considerados desafortunados intensifica-se pela carga emocional que the é imputada: "a capacidade de exposição de sentimentos também vem sendo uma das formas de autenticar tanto o testemunho e a confissão quanto a experiência narrada" (Ribeiro e Sacramento, 2020: 11).

\section{"CAMINHAR COM MÁSCARAS E FALAR PARA A TELEVISÃO NÃO É FÁCIL"10}

0 analisarmos o JN com a lente cronotópica, identificamos que, no contexto da pande-
mia, determinados lugares encontram-se encarnados em corpos, gestos e expressões faciais. No isolamento, o tempo e a materialidade dos encontros físicos cotidianos reforçam ainda mais a relação com a voz e o rosto daqueles que testemunham, sejam eles âncoras do telejornal, sejam profissionais da saúde.

Para Mikhail Bakhtin, o corpo é discurso, apresenta uma cultura corporal constantemente regenerada; torna-se amálgama de coisas, ambientes, de outros corpos. Se corpo é material e discursivo, ele é em si mesmo um objeto das relações entre sujeitos. Por isso, como nosso corpo dialoga com o olhar do outro, nós comunicamo-nos com outros corpos e nos constituímos, em um movimento sem fim, nos diversos espaços-tempos que perfazem encontros e existências na história.

Essa percepção corpórea de Bakhtin, durante a pandemia de COVID-19, encontra-se com lugares de memória que habitam também sensações físicas de nossa vida em sociedade. A presença de vestígios, encontros, agendas, gestos vitais, testemunhos que garantem a autenticidade de nossas vidas no espaço-tempo, são emoções, obrigações, novidades que formam pequenos ensaios do cotidiano.

Por isso, sentimos necessidade de mapear possíveis cronotopos recorrentes em edições selecionadas do JN. A catástrofe da pandemia provocou - e permitiu - mudanças no modelo narrativo, que passou a destacar ainda mais a presença de gestos de intimidade e afetabilidade de seus locutores, assim como novos ângulos de imagens, com diferentes qualidades, e quadros em que o testemunho prevalece. Há sobrevalorização do espaço íntimo dos personagens e do trânsito de afetos, em um processo de reconfiguração simbólica das esferas de tempo-espaço. 


\section{CRONOTOPOS DA QUARENTENA: O ROSTO, O GESTO E O AQUI DENTRO}

o dia 17 de março, a Rede Globo decidiu mudar a programação e passou a ter 11 ho-
ras de jornalismo diário. Era o início da quarentena no Brasil. Na edição do dia 23 de março, Renata Vasconcellos pede calma à população, reafirma a necessidade de ficar em casa e diz que os jornalistas trabalharão para levar informação de tudo o que ocorre no Brasil e no mundo 24 horas por dia para todos: "a informação é tão importante como lavar as mãos"11.

Mas, afinal, é certo dizer que a pandemia provocou alterações no JN? Ao analisarmos algumas edições do JN identificamos mudanças em enquadramentos, gestos, narrativas e qualidade de imagens que foram aceitas e exibidas. Não defendemos que tenha sido inicialmente uma estratégia diante da nova audiência que surgia, mas que foi se reafirmando com base nessa realidade.

Como roteiro para nossa observação, adotamos duas categorias como possibilidades de diálogo entre memórias dos corpos gravados e enquadrados na tela da televisão e memórias construídas sobre interior e exterior - casa/rua. Nossa intenção é pensar nas subjetividades tecidas na rearticulação de tempos e espaços com base nas notícias que chegam pelo telejornal e nos fortes efeitos de identificação com cronotopos. Dois pontos nodais que se articulam em uma trama relacionada a consumos, hábitos e acontecimentos. De março a junho, as categorias por nós escolhidas são gradativamente construídas em correlação direta com o aumento de casos de contaminação e mortes provocadas pelo novo coronavírus.

A primeira delas constitui-se em torno de memórias do corpo, um cronotopo da dimensão sensorial. Era preciso acessar o acervo de imagens de rostos, gestos e tons de voz que suscitassem um lugar-tempo de expressões para além de máscaras e medos. A segunda forma-se ao redor de memórias de espacialidades, tecendo a intersecção do interior e do exterior de lugares e vidas.

Para desenvolvermos essas relações torna-se importante especificarmos a concepção de afeto com a qual trabalhamos na análise do JN. Patricia Clough (2007) defende que o afeto se refere de maneira geral às capacidades corporais de afetar e ser afetado ou ao aumento ou diminuição da capacidade de um corpo de agir, engajar-se, conectar-se ao que o cerca a partir de registros de ações e contextos passados, conservados e repetidos. São saberes e memórias que carregamos nos sentidos de nossos corpos:

0 afeto é também teorizado em relação às tecnologias que nos permitem tanto "ver" o afeto quanto produzir capacidades corporais afetivas para além das constrições orgânico-fisiológicas do corpo. A experimentação tecnocientífica com o afeto não somente atravessa a oposição do 
orgânico e do não-orgânico; ela também insere o técnico na vitalidade sentida, vivacidade sentida dada nas capacidades corporais pré-individuais de agir, de engajar, de conectar - de afetar e ser afetado. A virada afetiva, logo, expressa uma nova configuração de corpos, tecnologia e matéria (Clough, 2007: 2).

Em memórias do corpo, a dimensão sensorial manifesta-se mais fortemente em 14 de maio. Com a marca de 844 mortes no dia e 13.999 no total confirmada pelo Ministério da Saúde, o JN faz uma mudança que explicita a escolha narrativa. Bonner explica que, desde o início, a imagem que ilustrava as matérias sobre a pandemia era a do coronavírus, "inimigo número um da humanidade neste momento":

Mas talvez a melhor forma de falar isso é lembrar que estamos falando de vidas, de cidadãos, de pessoas. Por isso, a partir de hoje, aquela imagem do inimigo número um [ele aponta para o fundo do cenário] vai sair do nosso painel. Em todos os momentos em que o Jornal Nacional estiver tratando da pandemia, vai estar lá atrás os rostos dos brasileiros que ela nos tirou. Esses sorrisos, olhares dos brasileiros que perdemos, podem ajudar a fortalecer a mensagem do que importa de verdade: a necessidade de proteger vidas (Jornal Nacional, 14 de maio de 2020).

A imagem de vírus, números e gráficos podem anular identificações porque não convocam presença física e sensorialidade de corpos, da concretude efetiva da vida, do que é tangível. Olhos e sorrisos passam a ser, principalmente diante de encontros com máscaras, pontos de reconhecimento de emoções e de inteligibilidade, e não mais gestos perecíveis.

A emoção é também reação física, e o corpo marca a tentativa de aproximar experiência e conhecimento, produzindo na opção pela estética narrativa outros afetos e potentes possibilidades de identificação (Leiroz, 2011). Na televisão, a imagem é parte intrínseca da enunciação, e incorporar, dar corpo a conceitos enunciados, tornou-se ainda mais urgente diante das limitações impostas pela quarentena.

A mão estendida de Renata Vasconcellos em direção a William Bonner é outro gesto que concretiza o afeto, por exemplo. Em 30 de abril, a última matéria do JN busca retratar a vida dos brasileiros durante a quarentena. Na Gávea, bairro do Rio de Janeiro (RJ), o repórter Pedro Bassan narra a emoção provocada na vizinhança de um prédio, no qual uma moradora, cantora lírica, entoa Ave Maria de sua janela após a badalada do sino da igreja do bairro às 18 horas.

As cenas captadas são enquadradas a partir de janelas, com declarações de moradores sobre o quanto esperavam aquele momento. 0 repórter interpreta a expectativa assim: "como se a vida ficasse em suspenso até que aquela janela se transforma em palco e enche a vida de esperança". 
Dentro de casa, rostos, vidas, aplausos, música. Fora de casa, ruas vazias e ansiedade. Vizinhos testemunham que a cantora marca o tempo em cotidiano de quarentena, "mais um dia vencido" ou "ela consegue nos lembrar de que a vida continua". Cabe a Bonner encerrar o JN, mas não consegue. "O Bonner ficou emocionado", diz Renata, apontando para ele. "Não, eu não. Quase não me emociono", responde Bonner, cruzando os braços e abaixando a cabeça. "Eu vou encerrar, tá?", completa a âncora.

Em edição anterior, de 25 de março, Bonner já havia levado a mão ao rosto depois de perguntar à Renata se ela estava cansada. "Estou, mas estou atenta e estamos serenos e vigilantes", respondeu Renata. E Bonner concluiu: "Eu também. A gente está cansado, você deve estar cansado também, está todo mundo cansado".

Mudanças de ordem discursiva e performática nos telejornais ocorrem há tempo. Estudos recentes sobre televisão têm percebido cada vez mais o protagonismo assumido por repórteres e apresentadores, incluindo narrativas sobre acontecimentos (Fausto Neto, 2012). Nos regimes de visibilidade do telejornalismo, tanto eles como outros sujeitos assumem função retórica de autenticação da realidade testemunhada. 0 ponto central da performance nas reportagens televisivas contemporâneas é a presença corporal do repórter, que atua como testemunha ao transformar a experiência em discurso, ou o visto no dito e no mostrado. A reportagem jornalística vem sendo cada vez mais baseada em narrativas de ação dramática, performática, por meio das quais o repórter, mais do que convidar o telespectador para tornar-se testemunha mediada pela televisão, passa a oferecer o depoimento de uma testemunha presencial na cena dos acontecimentos, o próprio repórter: "essa nova performance do jornalista mudou o status do testemunhal de sua atividade, que passou a se afirmar [...] mais pelo que ele viveu, experimentou" (Ribeiro e Sacramento, 2020: 61-62). É o repórter que passou a atuar por meio de uma persona que mistura um eu/sujeito com história, emoções e gestos pessoais particulares a um eu/repórter construído a partir de convenções corporais e discursivas sobre o telejornalismo. Ou seja, "se antes a regra era apresentar-se enquanto ventríloquo do fato, hoje o corpo do repórter também é explorado como lugar de performatização do acontecimento narrado" (Gutmann, 2014: 167)12.

Leonor Arfuch (2010: 74) afirma que o conceito de valor biográfico, "esse cronotopo da vida" , manifesta-se em diversas formas narrativas e de subjetivação contemporânea investida de autenticidade. No registro audiovisual, assim como no gráfico, os diversos momentos biográficos nas narrativas midiáticas tentam dar conta do "isso aconteceu" pela boca de seus protagonistas: "talvez seja onde se manifesta, com maior nitidez, a busca da plenitude da presença - corpo, rosto, voz - como proteção inequívoca da existência". 
Memórias do corpo absorvem a proeminência do vivencial e a necessidade obsessiva da certificação, de testemunho, da urgência do ao vivo e do tempo real, da imagem transcorrendo para a câmera comprovando e reafirmando o efeito da vida real que fortalece essa estratégia narrativa. Mais do que nunca, a intimidade deve ser invadida pelas emoções do mundo e da rua: minha casa recebe as sensações dos corpos - meus, seus, nossos - pelo JN.

A matéria sobre a oração na Gávea também serve como ponto de partida para apresentarmos a segunda possibilidade, que estaria nas memórias de espacialidades, tecendo na intersecção do interior e do exterior de lugares e vidas um cronotopo que enreda tanto o corpo como território quanto espaços concretos de casa e trabalho.

Ali estão intensificados imagens e enquadramentos que retratam o limite físico do espaço e o desejo de expansão e reorganização — janelas, telas, grades, o olhar da janela que enxerga a copa das árvores e outras pessoas com a distância também de grades, telas e janelas - , em um ímpeto de agregar objetos exteriores como parte de nossa privacidade.

0 auge dessa proposta vem com a criação do quadro "Aqui Dentro", em 11 de maio, protagonizado por profissionais da área de saúde. 0 próprio nome já propõe a intimidade pública e a suspensão de distâncias. A maior parte dos testemunhos é apresentada com uma moldura circular - diferente da geometria de janelas e formatos de telas de televisão - e incorpora imagens de baixa resolução, algumas feitas nitidamente de celulares, com pessoas usando roupas de trabalho, aventais e uniformes típicos do universo da saúde, sem produção ou maquiagem, em lugares que estão longe do alcance de nossos olhos e atrás das portas dos hospitais. Trata-se de uma estilização visual das formas no espaço televisivo.

Memórias de espacialidades, nesse contexto, envolvem ainda mais o testemunho, considerado principalmente sob as perspectivas comunicacionais e midiáticas, e a força da enunciação do eu. Os profissionais de saúde são apresentados com base em seus nomes completos, suas especialidades e seus locais de trabalho: são médicas, enfermeiros, fisioterapeutas, cirurgiões-dentistas, fonoaudiólogas de todas as regiões do Brasil. Falam dentro de salas de cirurgia, corredores de Unidade de Terapia Intensiva, consultórios, hospitais. Vemos pela janela e reconhecemos espaços já antes proibitivos e que agora carregam a simbologia do perigo.

Nós, espectadores, tornamo-nos também testemunhas impotentes diante dos acontecimentos que se desdobram. No entanto, somos amalgamados com as três possibilidades que o testemunho comporta para Frosh (2009): a inscrição de testemunhas nas narrativas midiáticas, as instâncias midiáticas enquanto testemunhas e o lugar testemunhal das audiências. A imagem captada pelo celular tem o enquadramento das selfies, com ruídos e falhas que atestam, para o público já acostumado com mensagens enviadas por aplicativos 
de conversas e compartilhamentos em redes sociais digitais, veracidade de um espaço-tempo (re)conhecido. No isolamento, os olhos cansados dos profissionais interagem com demandas imaginativas que suas falas de dentro do front fazem para seus destinatários: dentro de casa, as falas como a de Cezar Augusto de Oliveira, médico, ajudam a harmonizar sensações contraditórias: "a pandemia não eliminou outras doenças"; " sou um neurocirurgião, mas a gente é especializado em gente" 13 .

Tanto os âncoras do JN como os profissionais que testemunham criam as presenças que nos enredam verbal, visual, referencial e virtualmente nos espaços (hospitais/casa) e no tempo presente. Essa presença não é apenas contada, mas reveladora de diferenças que nos mobilizam como testemunhas também de uma experiência de isolamento, cúmplices de afetos em tempos pandêmicos: nós e os âncoras do $J N$ compartilhamos, pelas estratégias audiovisuais do "Aqui Dentro", a sensação corporal e a experiência de quem fala o que vive e sobrevive à catástrofe que nos assola, transmitindo o que conhecem.

Diante das câmeras, os profissionais de saúde reforçam o quanto sua presença permite maior reconhecimento de veracidade da experiência narrada, reforçada pelo fato de estarem no local de trabalho. Nesse ponto, "Aqui Dentro" é tanto um convite a saber detalhes sobre a atividade dos profissionais de saúde em seus locais de trabalho quanto a conhecer seus sentimentos, suas emoções, seus sofrimentos e suas alegrias diante da catástrofe imposta pela pandemia.

Os dois cronotopos - o hospital e a casa — parecem querer reativar um território já percorrido pelo telespectador, que dá conta da ambiguidade e complementaridade do dentro e do fora, da intimidade que deve ser compartilhada, que, mesmo exteriorizada em ambiente potencialmente infectado e insalubre, porque pandêmico, permitimos que entre e crie laços na intimidade de nossas casas. A união de espaço-tempo e afetividade parece querer ativar também saberes e memórias que perpassam nossos corpos, sentidos e espaços que eles ocupam no tempo.

\section{CONSIDERAÇÕES FINAIS}

nova intimidade há muito saiu do espaço doméstico tradicional para uma multiplicidade
de outros espaços e outras formas de vida. Nesse sentido, ao nos atermos a duas entre muitas possibilidades de interpretar notícias da pandemia a partir do JN com base em cronotopos de memórias de corpo e espacialidades, trabalhamos com âncoras de intimidade que implodem dualidades de uma interioridade sem portas e janelas dentro das especificidades dos discursos apresentados na televisão. 
Entendemos que essa estratégia narrativa tenha relação direta com o aumento de credibilidade e de audiência. De acordo com outra pesquisa, dessa vez feita pelo Datafolha durante a pandemia, o JN superou audiência de novela das $21 \mathrm{~h}$, atingindo 50,3 pontos na medição de audiência do lbope ${ }^{14}$.

Nessa dinâmica, continua válido aquilo que Mikhail Bakhtin (1998: 106) considerou sobre os gêneros do discurso: "o gênero sempre é e não é ao mesmo tempo, sempre é novo e velho ao mesmo tempo". 0 espaço de momentos biográficos, na repetição incansável e ritualizada de gestos inerentes ao cotidiano - e outros novos impostos pelas regras da quarentena, como entregar microfone para o entrevistado — - permite, em momentos de crises e catástrofes, a suspensão temporal, a abstração sensorial, unindo estranhamento e familiaridade.

A imagem de repórteres na rua, de máscara, acompanhando uma manifestação contra o racismo em plena pandemia, sozinhos, de mochila nas costas, filmando com seus celulares e narrando de forma ofegante, ao vivo para televisão, ao mesmo tempo que nos passa a concretude do corpo e da informação da rua, também incorpora imagens e subjetividades.

Há nessa proposta a possibilidade de compreender e aceitar que toda concepção de história e de cultura é sempre e inexoravelmente acompanhada de certa experiência do tempo que lhe está implícita e que a condiciona. No recorte temporal do período de maior isolamento social, o tempo midiático foi o que nos manteve em articulação com a cronologia de nosso momento, contada no relato catastrófico de mortes, em testemunhos e no apelo da lembrança de emoções e memórias de gestos por meio da televisão.

Não temos dúvida de que o significado dos eventos presentes ou passados tem importância na produção e na circulação de interpretações sobre os eventos narrados de modo a contribuir para a formação da memória coletiva. Ou seja, menos do que narrar sobre um tempo suspenso ou interrompido pela pandemia, o telejornal buscou, por meio de testemunhos, estruturar um significado (construído) que busca fazer a memória sobre essa pandemia perdurar no tempo. Trata-se, assim, de um tempo significativo para a história contemporânea, inédito e aparentemente sem precedentes.

Por outro lado, num contexto social marcado por múltiplos negacionismos, inclusive da própria gravidade da COVID-19, do adoecimento e do número de mortos pela doença, o uso das emoções e a presença emocionada dos profissionais de saúde diante das câmeras do $J N$, com o "Aqui Dentro", mostram o quanto a exposição do sofrimento sentido, da experiência pessoal, é cada vez mais acionada como estratégia para ter a narrativa validada como verdadeira. Cada vez mais em nossa cultura — o telejornalismo faz parte disso — - a verdade vem sendo colocada como da ordem do agenciamento emocional. Ter o narrado reconhecido como verdadeiro também é, em nossos tempos, narrar de modo emocionado e emocionante. 
Conflitos de interesse: nada a declarar.

Fonte de financiamento: Conselho Nacional de Desenvolvimento Científico e Tecnológico por meio da bolsa de produtividade e do edital universal.

Contribuições dos autores: Leiroz, F. P.; Sacramento, I.: Administração do Projeto, Análise Formal, Conceituação, Curadoria de Dados, Escrita - Revisão e Edição. Leiroz, F. P.: Escrita - Primeira Redação.

\section{NOTAS}

1 Disponível em: <https://mapabrasileirodacovid.inloco.com.br/pt/>. Acesso em: 30 dez. 2020.

2 Ver: <https://www.meioemensagem.com.br/home/opiniao/2020/06/04/opiniao-tv-em-tempos-de-pandemia.html>. Acesso em: 10 dez. 2020.

3 Pesquisas ainda indicam o JN como o segundo programa de maior audiência do horário nobre da televisão aberta, apesar de pequena queda da audiência a partir de setembro de 2020 (ver: <https://www.kantaribopemedia.com/audiencia-do-horario-nobre-15-mercados-14-12-a-20-12-2020/>. Acesso em: 23 dez. 2020).

4 Ver: <https://telepadi.folha.uol.com.br/jornal-nacional-ganhou-mais-de-15-milhao-de-jovens-por-dia-napandemia/>. Acesso em: 20 dez. 2020.

5 A diferença no aumento da audiência relacionada a diferenças socioeconômicas reforça 0 perfil de pessoas que puderam ficar em casa e daquelas, independentemente de sua ocupação ser ou não considerada essencial durante a quarentena, que não puderam.

6 Frase de Magaly Moraes de Souza, entrevistada em sua casa para o JN de 30 de abril de 2020. Disponível em: <https://globoplay.globo.com/v/8523307/programa/>. Acesso em: 5 nov. 2020.

7 Frase da fisioterapeuta intensivista Danielle Neiva de Aquino no quadro "Aqui Dentro", do JN, exibido em 3 de junho 2020. Disponível em: <https://globoplay.globo.com/ v/8601134/?s=0s>. Acesso em: 5 nov. 2020.

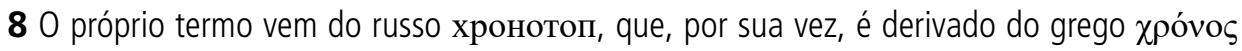

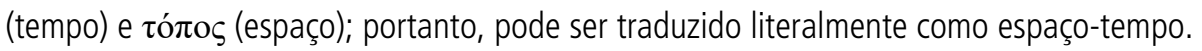

9 Fala de Débora Abdala, especialista em clínica médica, na edição de 2 de junho de 2020 no quadro "Aqui Dentro", do JN. Disponível em: <https://globoplay.globo.com/ v/8598396/?s=0s>. Acesso em: 5 nov. 2020. 
10 Fala de Bonner sobre a dificuldade de repórteres em uma cobertura ao vivo, no dia 2 de junho de 2020. Disponível em: <https://globoplay.globo.com/v/8598394/?s=0s>. Acesso em: 10 nov. 2020.

11 Os cuidados necessários para se proteger da contaminação pelo vírus incluem uso de máscaras, lavar as mãos sempre que possível ou usar álcool em gel.

12 É difícil identificar um ponto de inflexão preciso para tal mudança na atuação do repórter diante das câmeras. Como apontam Marialva Barbosa e Ana Paula Goulart Ribeiro (2005), nos anos 1980, a popularização do videoteipe e a comercialização de câmeras e equipamentos de gravação mais leves é uma das explicações possíveis para a maior presença do repórter não só diante da câmera, mas também em movimento diante delas. No telejornalismo brasileiro contemporâneo, segundo Juliana Gutmann (2014), a constituição da isenção implicava um tipo específico de performance baseada no controle das expressões corporais e da entonação, mais monótona e monocromática, com volume e tessitura restritos (o repórter-ventríloquo). 0 que há de diferença no atual contexto comunicativo do telejornalismo, segundo a autora, está no fato de que a performance tornou-se um valor jornalístico (o repórter-persona). Aqui, há um processo bem mais intenso de modalização enunciativa da linguagem telejornalística.

13 Disponível em: <https://globoplay.globo.com/v/8678606/>. Acesso em: 5 mar. 2021.

14 Ver: <https://trendings.com.br/comunicacao/audiencia-do-jornalismo-cresce-durante-o-isolamento-social/>. Acesso em: 10 dez. 2020.

\section{REFERÊNCIAS BIBLIOGRÁFICAS}

ARFUCH, L. Cronotopias de la intimidad. In: ARFUCH, L. (org.). Pensar este tiempo: espacios, afectos, pertenencias. Buenos Aires: Paidós, 2005. p. 237-290.

ARFUCH, L. O espaço biográfico: dilemas da subjetividade contemporânea. Rio de Janeiro: Ed. UERJ, 2010.

BAKHTIN, M. Questões de literatura e estética - a teoria do romance. São Paulo: Editora da UNESP, 1998.

BAKHTIN, M. Teoria do romance II: as formas do tempo e do cronotopo. São Paulo: Editora 34, 2018.

BARBOSA, M. Percursos do olhar: comunicação, narrativa e memória. Niterói: EDUFF, 2007.

BARBOSA, M. Tempo, tempo histórico e tempo midiático: inter-relações. In: MUSSE, C. F.; VARGAS, H.; NICOLAU, M. (orgs.). Comunicação, mídias e temporalidades. Salvador: EDUFBA, 2017. p. 19-36.

BARBOSA, M.; RIBEIRO, A. P. G. Telejornalismo na Globo: vestígios, narrativas e temporalidades. In: BRITTOS, V.; BOLAÑO, C. (orgs.). TV Globo: 40 anos de poder e hegemonia. São Paulo: Paulus, 2005. p. 205-224.

CLOUGH, P. The affective turn: theorizing the social. Durham: Duke University Press, 2007. 
FAUSTO NETO, A. Transformações nos discursos jornalísticos: a atorização do acontecimento. In: MOUILLAUD, M.; PORTO, S. D. (orgs.). 0 jornal: da forma ao sentido. Brasília: Editora UnB, 2012. p. 200-217.

FROSH, P. Telling presences: witnessing, mass media, and the imagined lives of strangers. In: FROSH, P; PINCHEVSKI, A. Media witnessing: testimony in the age of mass communication. Basingstoke: Palgrave MacMillan, 2009. p.49-72.

GUTMANN, J. F. Formas do telejornal: linguagem televisiva, jornalismo e mediações culturais. Salvador: EDUFBA, 2014.

JORNAL NACIONAL, 06 de maio de 2020. Disponível em: <https://globoplay.globo.com/v/8536435/ programa/>. Acesso em: 05 nov. 2020.

JORNAL NACIONAL, 14 de maio de 2020. Disponível em: <https://globoplay.globo.com/v/8554917/ programa/>. Acesso em: 2 nov. 2020.

JORNAL NACIONAL, 20 de junho de 2020. Disponivel em: <https://globoplay.globo.com/v/8641367/ programa/>. Acesso em: 05 nov. 2020.

LEIROZ, F. Ego-histórias: repertórios teóricos alternativos. 2011. 11f. Tese (Doutorado em Letras) - Faculdade de Letras, Pontifícia Universidade Católica do Rio de Janeiro, Rio de Janeiro, 2011.

POMIAN, K. Catástrofe. In: Enciclopédia Einaudi. v. 2. Turim: Einaudi, 1977. p. 789.

RIBEIRO, A. P. G..; SACRAMENTO, I. Televisão e memória: entre testemunhos e confissões. Rio de Janeiro: MauadX, 2020.

RIBEIRO, A. P. G. et al. A catástrofe como tragédia: da metonímia à sinonímia. In: MAIA, J. et al. (orgs.). Catástrofes e crises do tempo: historicidades dos processos comunicacionais. Belo Horizonte: Fafich/UFMG, 2020. p. 53-80.

RICOEUR, P. A memória, a história, o esquecimento. Campinas: Editora da UNICAMP, 2007.

SILVERSTONE, R. Mediating catastrophe: September 11 and the crisis of the other. In: ZELIZER, B.; ALLAN, S. Journalism after September 11. London: Routledge, 2011. p. 75-81.

SIMMEL, G. El individuo y la libertad. Barcelona: Península, 1986.

VEYNE, P. Como se escreve a história. Lisboa: Edições 70, 1971. 